\title{
On photocatalytic membrane reactors in water and wastewater treatment and organic synthesis
}

\author{
Sylwia Mozia \\ West Pomeranian University of Technology, Szczecin, Institute of Inorganic Technology and \\ Environment Engineering, Pułaskiego 10, 70-322 Szczecin, Poland
}

\begin{abstract}
A brief overview of hybrid photocatalysis-membrane processes and their possible applications in water/wastewater treatment and organic synthesis is presented. Moreover, a short introduction to photocatalysis is shown. The paper summarizes the main advantages and disadvantages of photocatalytic membrane reactors (PMRs) with photocatalytic membranes or a photocatalyst in suspension. Furthermore, the influence of photocatalysis on membranes performance in terms of fouling and efficiency of removal of organic contaminants during treatment of water and wastewater is discussed. In the second part of the review the examples showing the possibilities of application of PMRs in recovery of valuable compounds (benzaldehyde, vanillin) or photocatalytic partial oxidation of benzene to phenol are presented. It was concluded that PMRs exhibit numerous advantages over the conventional photoreactors, however, further investigations are still needed in order to improve the hybrid processes performance.
\end{abstract}

Keywords: photocatalytic membrane reactor, photocatalysis, membrane, hybrid process, water treatment, organic synthesis

\section{Introduction to photocatalytic membrane reactors}

In recent years a significant attention has been directed to the photocatalytic membrane reactors (PMRs) being hybrid systems coupling photocatalysis and membrane separation. Photocatalysis is one of Advanced Oxidation Processes (AOPs), i.e. processes based on the generation of very reactive oxidizing species such as hydroxyl radicals $\left(\mathrm{OH}^{*}\right)$. According to IUPAC recommendations [1] photocatalysis is defined as a "change in the rate of a chemical reaction or its initiation under the action of ultraviolet, visible, or infrared radiation in the presence of a substance - the photocatalyst - that absorbs light and is involved in the chemical transformation of the reaction partners". Further, a photocatalyst is a "substance able to produce, by absorption of ultraviolet, visible, or infrared radiation, chemical transformations of the reaction partners, repeatedly coming with them into intermediate chemical interactions and regenerating its chemical composition after each cycle of such interactions" [1]. In case of heterogeneous photocatalysis such photocatalysts are solid semiconductors amongst which $\mathrm{TiO}_{2}$, due to its high photoactivity and stability is the most commonly used.

A simplified idea of photocatalysis is presented schematically in Fig. 1 


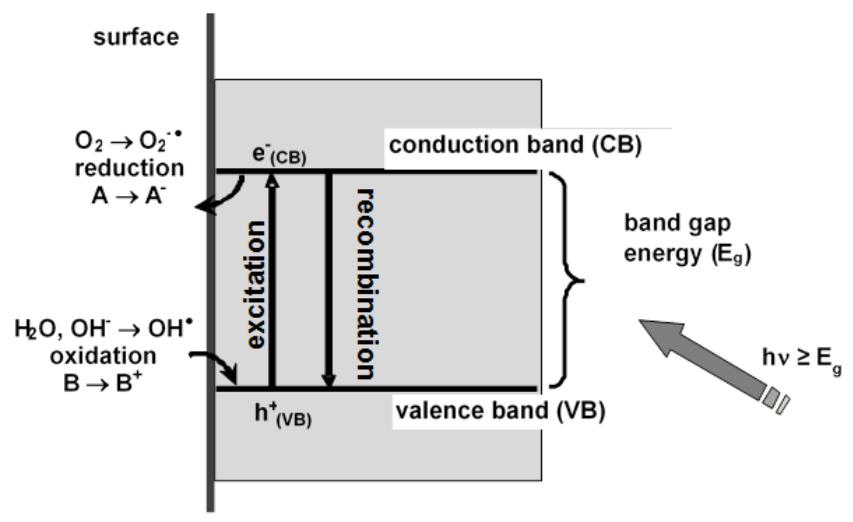

Fig. 1. Idea of photocatalysis: A, electron acceptor; B, electron donor [2].

The photoinduced reactions are activated by absorption of a photon (hv) with sufficient energy, i.e. equal or higher than the band gap energy $\left(E_{g}\right)$ of the photocatalyst [2]. In case of anatase phase $\mathrm{TiO}_{2}$ the $\mathrm{Eg}$ amounts to $3.23 \mathrm{eV}$ which corresponds to the wavelength of 384 $\mathrm{nm}$. This means that UV irradiation is necessary to realize the photocatalytic process with application of $\mathrm{TiO}_{2}$.

After the absorption of a photon (Fig. 1) an electron ( $\mathrm{e}^{-}$) may be promoted from the valence band (VB) to the conduction band (CB) thus generating an electron vacancy - "hole" $\left(\mathrm{h}^{+}\right)$:

$\mathrm{TiO}_{2}+\mathrm{h} v \rightarrow \mathrm{TiO}_{2}\left(\mathrm{e}_{\mathrm{CB}}^{-}+\mathrm{h}_{\mathrm{VB}}{ }^{+}\right)$

The electron and the hole can migrate to the surface of the photocatalyst and participate in redox reactions:

$$
\begin{aligned}
& \mathrm{TiO}_{2}\left(\mathrm{~h}_{\mathrm{VB}}^{+}\right)+\mathrm{H}_{2} \mathrm{O} \rightarrow \mathrm{TiO}_{2}+\mathrm{H}^{+}+\mathrm{OH}^{\cdot} \\
& \mathrm{TiO}_{2}\left(\mathrm{~h}_{\mathrm{VB}}{ }^{+}\right)+\mathrm{OH}^{-} \rightarrow \mathrm{TiO}_{2}+\mathrm{OH}^{\cdot} \\
& \mathrm{TiO}_{2}\left(\mathrm{e}_{\mathrm{CB}}{ }^{-}\right)+\mathrm{O}_{2} \rightarrow \mathrm{TiO} 2+\mathrm{O}^{--} \\
& \mathrm{O}_{2}^{\cdot-}+\mathrm{H}^{+} \rightarrow \mathrm{HO}_{2}^{\cdot} \\
& \mathrm{HO}_{2}{ }^{-}+\mathrm{HO}_{2}^{\cdot} \rightarrow \mathrm{H}_{2} \mathrm{O}_{2}+\mathrm{O}_{2} \\
& \mathrm{TiO}_{2}\left(\mathrm{e}_{\mathrm{CB}}{ }^{-}\right)+\mathrm{H}_{2} \mathrm{O}_{2} \rightarrow \mathrm{OH}^{\cdot}+\mathrm{OH}^{-} \\
& \mathrm{H}_{2} \mathrm{O}_{2}+\mathrm{O}_{2}{ }^{-} \rightarrow \mathrm{OH}^{\cdot}+\mathrm{OH}^{-}+\mathrm{O}_{2} \\
& \mathrm{H}_{2} \mathrm{O}_{2}+\mathrm{hv} \rightarrow 2 \mathrm{OH}^{\cdot}
\end{aligned}
$$

The hydroxyl radicals $\left(\mathrm{OH}^{*}\right)$ are supposed to be the primary oxidizing species in the photocatalytic oxidation processes [2].

The role of photocatalysis in PMRs is degradation of organic substances while the membrane might act as a simple barrier for the photocatalyst and as a selective barrier for the degraded molecules and products/by-products of their decomposition [2].

There are various configurations of PMRs [2,3]. Based on the way in which the photocatalyst is introduced to the system the PMRs can be divided into (I) reactors with 
photocatalyst suspended in feed solution and (II) reactors with photocatalyst supported in/on the membrane. In case (I) three main configurations can be distinguished, dependent on which element of the installation works as a photoreactor: (a) PMRs with the irradiation source above/in the feed tank, (b) PMRs with the irradiation source above the membrane module and (c) PMRs with the irradiation source above/in an additional reservoir (photoreactor) positioned between the feed tank and the membrane module. In case of PMRs with photocatalytic membranes, the light source must be located in the vicinity of the membrane since the photoreaction takes place on the membrane surface and within its pores. There are also configurations in which the light sources are located above both membrane module and feed tank (or inside them, when immersed UV lamps are used). The PMRs design is affected by numerous factors. They include process mode (dead end or cross-flow, batch or continuous flow, etc.), type of the membrane technique applied (e.g. microfiltration (MF), ultrafiltration (UF), nanofiltration (NF), membrane distillation (MD), pervaporation (PV), dialysis), construction of the membrane modules (flat sheet, tubular, submerged, etc.) and the type of the irradiation source.

The main directions of application of PMRs are water and wastewater treatment, however, the possibilities of utilization of these systems in chemical synthesis are also considered.

\section{PMRs in water and wastewater treatment}

Both PMRs with photocatalytic membranes and PMRs with a photocatalyst in suspension were proposed to treat water and wastewater. PMRs with photocatalytic membranes have been applied for removal of different organic compounds such as sodium dodecylbenzene sulfonate, dyes (methylene blue, direct black, methyl orange, congo red, etc), herbicides, phenols, chlorophenols, 4-nitrophenol, humic acids and others as well as for disinfection purpose $[2,4]$. It was also proved that $\mathrm{TiO}_{2}$-coated membranes exhibited selfcleaning properties under the action of UV irradiation [5].

There are two main types of photocatalytic membranes: (a) with a photoactive layer, which fulfils also the function of a separation layer, and (b) with a non-photoactive separation layer deposited on a photoactive support. Depending on the membrane type, the irradiation source is positioned either on the feed side or on the permeate side. The main advantage of configuration (a) is that membrane fouling could be reduced and permeate flux increased. This is due to the decomposition of organic compounds responsible for the formation of the gel layer and filtration cake (e.g. humic and fulvic acids). It was also reported that modification of the membranes with $\mathrm{TiO}_{2}$ resulted in an increase in their hydrophilicity, which also contributed to fouling mitigation [3]. The configuration (b) is less common. The main disadvantage of the membranes with the photoactive support and a non-photoactive skin layer is that the purified stream is permeate only, whereas the concentrate contains contaminants which were rejected by the membrane. However, in this system it is possible to obtain permeate of much higher quality than in the configuration (a) $[2,3]$.

Taking into account that in case of the photocatalytic membranes the light source must be located in the vicinity of the membrane and that the photocatalytic reactions occur on the membrane surface or within its pores, the membrane should exhibit high resistance to UV irradiation and oxidation by hydroxyl radicals or other reactive oxygen species. Therefore, inorganic membranes (ceramic or metallic) are more promising for the application in PMRs than the polymeric ones.

A brief summary of advantages and disadvantages of PMRs with photocatalytic membranes is presented in Table 1 . 
Table 1. Advantages and disadvantages of PMRs with photocatalytic membranes $[2,3]$.

\begin{tabular}{|c|c|}
\hline Advantages & Disadvantages \\
\hline $\begin{array}{l}\text { No need to separate and recycle a } \\
\text { photocatalyst - the membrane can be used } \\
\text { as long as the activity of the photocatalyst } \\
\text { remains high }\end{array}$ & $\begin{array}{l}\text { In case of aqueous phase reactions the } \\
\text { effectiveness of degradation lower than in } \\
\text { case of photocatalyst in suspension }\end{array}$ \\
\hline $\begin{array}{l}\text { Possibility of fouling mitigation due to } \\
\text { decomposition of organic contaminants } \\
\text { forming the gel layer or filtration cake }\end{array}$ & $\begin{array}{l}\text { Adjustment of photocatalyst loading to the } \\
\text { composition of the treated solution is } \\
\text { impossible (fixed amount of the } \\
\text { photocatalyst immobilized in/on the } \\
\text { membrane) }\end{array}$ \\
\hline $\begin{array}{l}\text { Possibility of fouling mitigation due to } \\
\text { enhanced hydrophilicity of the } \mathrm{TiO}_{2-}^{-} \\
\text {modified membrane }\end{array}$ & $\begin{array}{l}\text { Risk of damage of polymeric membranes by } \\
\text { UV light or hydroxyl radicals }\end{array}$ \\
\hline $\begin{array}{l}\text { No membrane fouling due to presence of } \\
\mathrm{TiO}_{2} \text { particles }\end{array}$ & $\begin{array}{l}\text { Necessity of the membrane exchange when } \\
\text { the photocatalyst loses its activity }\end{array}$ \\
\hline $\begin{array}{l}\text { Contaminants could be decomposed either } \\
\text { in feed or in permeate }\end{array}$ & $\begin{array}{l}\text { Complicated construction of membrane } \\
\text { modules - the radiation must reach the } \\
\text { membrane surface }\end{array}$ \\
\hline
\end{tabular}

In most configurations of PMRs with a suspended photocatalyst the pressure driven membrane techniques such as microfiltration (MF) and ultrafiltration (UF) are applied. There are also other types PMRs in which photocatalysis is combined with nanofiltration (NF), dialysis, pervaporation (PV) or direct contact membrane distillation (DCMD, MD) [2, 3]. The main role of a membrane in these systems is separation of photocatalyst particles from the treated solution. Moreover, depending on the membrane type and membrane process applied, the membrane might also act as a barrier for the degraded molecules and products of their decomposition.

PMRs coupling photocatalysis with pressure driven membrane techniques have been applied for the removal of various pollutants, including pharmaceuticals, humic and fulvic acids, trichloroethylene, bisphenol A, chlorophenol, 4-nitrophenol, dyes, as well as for treatment of real dyeing wastewater, synthetic wastewater, grey water, primary and secondary effluents from municipal wastewater treatment plants and surface waters $[3,6]$. Both pressurized and depressurized (i.e. with submerged membranes) systems were applied. It is usually reported that the main drawback of the pressurized PMRs is membrane fouling caused by $\mathrm{TiO}_{2}$ particles leading to the permeate flux deterioration. However, operation below the critical flux value can prevent from deposition of the $\mathrm{TiO}_{2}$ cake layer on the membrane surface [7]. In general it is reported that the PMRs with submerged membranes are less prone to fouling by $\mathrm{TiO}_{2}$ than the pressurized systems. This does not mean, however, that fouling does not occur in these systems at all. The investigations on the treatment of river water in a PMR utilizing submerged MF membranes revealed [8] that although photocatalysis had a beneficial influence on the permeate flux, a chemical cleaning after about one month of operation was necessary.

It must be remembered that membrane fouling by $\mathrm{TiO}_{2}$ is a complex issue and there are numerous factors affecting this phenomenon. They include feed composition and $\mathrm{pH}$, hydraulic conditions (cross flow velocity, transmembrane pressure), operating mode (pressurized, depressurized), operating conditions in membrane module (aeration, intermittent permeation, gas backflushing), etc. [2,3]. Analyzing the reports on the hybrid photocatalysis 
- membrane systems published in recent years it can be concluded that the influence of $\mathrm{TiO}_{2}$ on permeate flux in PMRs is dual [6]. From one side, in the presence of $\mathrm{TiO}_{2}$ a deterioration of the flux resulting from the formation of a cake layer on a membrane surface can take place, as was mentioned above. From the other hand, when the feed contains contaminants such as natural organic matter (NOM), especially humic and fulvic acids, the coupling of a membrane process with photocatalysis can lead to the improvement of the flux due to decomposition of organic molecules. A positive influence of photocatalysis on the permeate flux during treatment of primary (PE) and secondary (SE) effluents from a municipal wastewater treatment plant in a pressurized PMR utilizing UF was also reported [6].

Table 2. Advantages and disadvantages of PMRs with suspended photocatalyst utilizing pressure driven membrane techniques $[2,3]$.

\begin{tabular}{|c|c|}
\hline Advantages & Disadvantages \\
\hline $\begin{array}{l}\text { The effectiveness of degradation higher than } \\
\text { in case of photocatalyst immobilized in/on } \\
\text { the membrane }\end{array}$ & $\begin{array}{l}\text { Membrane fouling due to the presence of } \\
\mathrm{TiO}_{2} \text { particles, especially in case of } \\
\text { pressurized systems }\end{array}$ \\
\hline $\begin{array}{l}\text { The exhausted photocatalyst might be } \\
\text { exchanged without membrane replacement }\end{array}$ & \multirow{6}{*}{$\begin{array}{l}\text { Low quality of permeate }- \text { initial } \\
\text { compounds and products/by-products of } \\
\text { their degradation pass through the } \\
\text { membranes, especially in case of MF and } \\
\text { UF }\end{array}$} \\
\hline $\begin{array}{l}\text { Easy adjustment of photocatalyst loading to } \\
\text { the composition of the treated solution }\end{array}$ & \\
\hline $\begin{array}{llll}\begin{array}{l}\text { Effective separation of photocatalyst } \\
\text { particles }\end{array} & & \\
\end{array}$ & \\
\hline $\begin{array}{l}\text { Possibility of enhancement of permeate flux } \\
\text { due to decomposition of NOM forming a gel } \\
\text { layer }\end{array}$ & \\
\hline $\begin{array}{l}\text { Possibility of enhancement of permeate flux } \\
\text { by application of depressurized (submerged) } \\
\text { systems instead of pressurized ones }\end{array}$ & \\
\hline $\begin{array}{l}\text { No risk of damage of polymer membranes } \\
\text { by the UV light or hydroxyl radicals - the } \\
\text { light source can be positioned anywhere in } \\
\text { the hybrid system }\end{array}$ & \\
\hline
\end{tabular}

The efficiency of removal of organic contaminants in PMRs utilizing MF or UF depends on the effectiveness of both the membrane process and photocatalysis. In general, MF and UF membranes are not able to reject low molecular organic compounds, including initial contaminants and by-products of their decomposition. Therefore, in case of these substances the overall treatment efficiency depends on the effectiveness of photocatalysis. On the other hand, since the mineralization of large molecules proceeds slowly, the overall treatment efficiency in case of such contaminants depends on the effectiveness of a membrane separation.

A brief summary of advantages and disadvantages of PMRs with suspended photocatalyst is presented in Table 2 .

\section{PMRs in organic synthesis}

A majority of literature reports on PMRs refers to their possible application in water and wastewater treatment. The aim of application of photocatalysis in these systems is mineralization of organic contaminants to nontoxic compounds such as $\mathrm{CO}_{2}, \mathrm{H}_{2} \mathrm{O}$ and 
inorganic salts (chlorides, nitrates, sulfates, etc.). Recently, however, some papers describing possibilities of utilization of PMRs in organic synthesis have also been published. In this approach a partial oxidation of organic compounds aimed at production of useful substances is mainly considered [9]. The proposed solutions include (i) recovery of valuable intermediate compounds (benzaldehyde and 4-methoxybenzaldehyde) produced from the corresponding alcohols (benzyl alcohol and 4-methoxybenzyl alcohol) in an integrated photocatalysis pervaporation system; (ii) recovery of vanillin produced by trans-ferulic acid oxidation using an integrated photocatalysis - pervaporation system; (iii) photocatalytic partial oxidation of benzene to phenol in a photocatalytic membrane reactor with application of benzene as both substrate and extracting agent [9]. It was reported [10] that the coupling of pervaporation with the photocatalytic partial oxidation of a primary aromatic alcohol to produce the corresponding aldehyde enhanced the rate and the yield of the process. The observed improvement resulted from a continuous recovery of the aldehyde from the reaction environment before its further oxidation. Similarly, the utilization of a highly selective membrane prepared from PEBAX ${ }^{\circledR} 2533$ (polyether block amide by Arkema) allowed the continuous recovery of vanillin from the reaction environment by means of pervaporation, so that its oxidative degradation was minimized and the yield was substantially enhanced [11]. Nonetheless, the idea of application of PMRs in organic synthesis is still in its early stages and much work should be done before a possible utilization of this technology on the industrial scale.

\section{Summary}

PMRs exhibit numerous advantages over the conventional photoreactors in case of both water and wastewater treatment as well as organic synthesis. However, further investigations are still needed in order to improve the hybrid photocatalysis - membrane processes performance, especially in terms of permeate flux and membrane fouling as well as product (permeate) quality.

Moreover, it is very important to investigate the real systems, which focus on the treatment of natural waters and real wastewaters. The number of reports concerning this subject is still limited, since most of the experiments have been conducted using model solutions.

Especially extensive investigations are necessary in the area of application of PMRs in organic synthesis. Since the idea is still in its early stages, much work should be done before a potential utilization of this technology on the industrial scale.

Nonetheless, the main obstacles in full scale application of PMRs are:

- the light source: development of photoreactors and photocatalysts efficiently utilizing solar light would be beneficial from the economic point of view;

- the membranes: development of membranes resistant to the severe conditions prevailing in PMRs, especially in terms of resistance to oxidation by hydroxyl radicals and other oxidative species as well as abrasion by photocatalyst particles is necessary.

\section{LITERATURE}

[1]. Braslavsky S. E., Braun A. M., Cassano A. E., Emeline A. V., Litter M. I., Palmisano L., Parmon V. N., Serpone N., Glossary of terms used in photocatalysis and radiation catalysis (IUPAC recommendations 2011), Pure Appl. Chem. 83 (2011) 931-1014.

[2]. Mozia S., Photocatalytic membrane reactors (PMRs) in water and wastewater treatment. A review, Sep. Purif. Technol. 73 (2010) 71-91.

[3]. Molinari R., Palmisano L., Loddo V., Mozia S., Morawski A. W., Chapter 21: Photocatalytic membrane reactors: configurations, performance and applications in water 
treatment and chemical production, in: Basile A. (Ed.) Handbook of Membrane Reactors. Reactor Types and Industrial Applications. Volume 2, Woodhead Publishing Limited, 2013, pp. 808-845, ISBN 978-0-85709-415-5.

[4]. Leong S., Razmjou A., Wang K., Hapgood K., Zhang X., Wang H., TiO2 based photocatalytic membranes: A review, J. Membrane Sci. 472 (2014) 167-184.

[5]. Song H., Shao J., He Y., Liu B., Zhong X., Natural organic matter removal and flux decline with PEG-TiO2-doped PVDF membranes by integration of ultrafiltration with photocatalysis, J. Membrane Sci. 405-406 (2012) 48-56.

[6]. Mozia S., Darowna D., Szymański K., Grondzewska S., Borchert K., Wróbel R., Morawski A. W., Performance of two photocatalytic membrane reactors for treatment of primary and secondary effluents, Catal. Today, 236A (2014) $135-145$.

[7]. Mozia S., Darowna D., Orecki A., Wróbel R., Wilpiszewska K., Morawski A. W., Microscopic studies on $\mathrm{TiO} 2$ fouling of $\mathrm{MF} / \mathrm{UF}$ polyethersulfone membranes in a photocatalytic membrane reactor, J. Membrane Sci., 470 (2014) 356-368.

[8]. Meng Y., Huang X., Yang Q., Qian Y., Kubota N., Fukunaga S., Treatment of polluted river water with a photocatalytic slurry reactor using low-pressure mercury lamps coupled with a membrane, Desalination, 181 (2005) 121-133.

[9]. Molinari R., Argurio P., Lavorato C., Review on reduction and partial oxidation of organics in photocatalytic (membrane) reactors, Curr. Org. Chem., 17 (2013) 2516-2537.

[10]. Camera-Roda G., Santarelli F., Augugliaro V., Loddo V., Palmisano G., Palmisano L., Yurdakal S., Photocatalytic process intensification by coupling with pervaporation, Catal. Today 161 (2011) 209-213.

[11]. Camera-Roda G., Augugliaro V., Cardillo A., Loddo V., Palmisano G., Palmisano L., A pervaporation photocatalytic reactor for the green synthesis of vanillin, Chem. Eng. J., 224 (2013) 136-143. 